\title{
Epidemiology of campylobacteriosis in a cohort of rural population near Calcutta
}

\author{
P. G. SEN GUPTA, G. B. NAIR, S. MONDAL, D. N. GUPTA, D. SEN, \\ S. N. SIKDAR, P. DAS, R. K. SARKAR, S. GHOSH, N. C. SAHA, B. C. DEB \\ AND S. C. PAL \\ National Institute of Cholera and Enteric Diseases, P-33, CIT Road, Scheme XM, \\ Beliaghata, Calcutta - 700 010, India
}

(Received 10 January 1991)

\section{SUMMLARY}

Over a 2-year period, 25 families comprising of 181 individuals of all ages were longitudinally observed for the excretion of Campylobacter species. Faecal samples were taken from all persons with diarrhoea. Specimens were also taken from apparently healthy individuals and from domestic animals living within the confines of the study families at monthly intervals.

The overall diarrhoea attack rate was 19 episodes per 100 person-years with peak incidence in the 1- to 4-year-old age group (76/100 person-years). Eight $(11.5 \%)$ of the total episodes were campylobacter-associated and the overall rate of campylobacter positive diarrhoeal episodes were 2.2 per 100 person-years. Of the 1002 stool samples from healthy individuals $32(3 \cdot 2 / 100$ samples) were positive for campylobacter. The organism was most frequently isolated from children under 1 year of age both during diarrhoeal episodes (11.5 per 100 person-years) and nondiarrhoeal (11.1 per 100 samples). Multiple infections in a family were rare. In $19.4 \%$ of the occasions one or more animals were campylobacter positive. However, only in $\mathbf{7 \cdot 7 \%}$ of these occasions was a human infection recorded within 1 month after the animal was found to be positive.

The study showed that the epidemiology of campylobacteriosis in this community was distinct compared to that observed in developed countries.

\section{INTRODUCTION}

Since the discovery of campylobacters as an important aetiologic agent of human diarrhoea $[1,2]$, the organism has been recovered with increasing frequency from diarrhocal stool in both developed and developing countries [3-6]. However, Campylobacter spp. are rarely isolated from healthy populations in developed countries [7] where outbreaks of campylobacter enteritis are regularly associated with contaminated undercooked food products especially chicken or with infected household pets $[8,9]$. The epidemiology of human campylobacteriosis in the setting of the developing country is less well understood.

A prospective study was undertaken to investigate the excretion of campylobacters in diarrhoeal and normal stools of a cohort of a rural population near Calcutta. 


\section{MIATERIALS AND METHODS}

Twenty-five families were selected in a rural community near Calcutta for a longitudinal study extending over a period of 2 years. A total of 181 individuals belonging to all age groups were monitored through a 6 days-a-week surveillance for episodes of diarrhoea. A fresh faecal specimen was collected from each case in sterile MacCartney bottles containing $5 \mathrm{ml}$ of fluid thioglycollate (Difco) supplemented with $0.1 \%$ dextrose, $0.16 \%$ agar and Skirrow's formulation of antimicrobials (Oxoid, Code No. SR 69). A portion of the stool was also collected in a sterile empty bottle for parasitological examination, and in Cary and Blair transport medium for the culture of other enteropathogens. Faecal samples from healthy subjects belonging to the same cohort, and from domestic animals living within the confines of the families under study were subjected to monthly screening. These samples were screened only for the presence of campylobacters.

Within 3-4 h of collection, the samples were plated on a selective medium containing Columbia Agar Base (BBL) with $15 \%$ defibrinated sheep blood and Butzler's formulation of antimicrobials (Oxoid, Code No. SR 85). The plates were incubated at $42{ }^{\circ} \mathrm{C}$ in candle extinction jars and examined at intervals of 24,48 and $72 \mathrm{~h}$. Campylobacter isolates were confirmed by Gram stain, typical motility, and by the oxidase, catalase, and hippurate hydrolysis tests [10]. The stool sample collected in Cary and Blair medium were cultured using standard laboratory procedures for the presence of Vibrio cholerae, Vibrio parahaemolyticus, diarrhoeagenic Escherichia coli, Shigella spp. and Salmonella sp. [11,12]. The samples were also examined by direct microscopic examination and after formol ether concentration [13] for intestinal parasites.

\section{RESULTS}

Diarrhoea was defined as three or more loose or watery stools or a single motion with blood and mucus in $24 \mathrm{~h}$. 'The age-specific attack rates of all diarrhoea, campylobacter associated diarrhoea and campylobacter inapparent infections are presented in Fig. 1. The rates have been expressed as 100 person-years of exposure for diarrhocal episodes and per 100 samples for campylobacter inapparent infections. The rates have been adjusted for age at the time of sampling. The overall attack rate in all age groups during 24 months of follow up was 19 episodes per 100 person-years (70 episodes/181 individuals/2 years) with a peak incidence in the 1-4 years age group (76 per 100 person-years). Eight $(11.4 \%$ ) of these episodes were campylobacter-associated. The overall rate of campylobacterpositive diarrhoeal episodes was $2 \cdot 2$ per 100 person-years. Of the 1002 stool samples collected from the same cohort during healthy periods, 32 ( $3 \cdot 2$ per 100 samples) were positive for campylobacter. The organism was most frequently isolated from children below 1 year of age during both diarrhoeal (11.5 per 100 person-years) and control (11.1 per 100 samples) periods. The corresponding rates in pre-school age groups was 5.9 and 9.5 , respectively. The older age groups showed comparatively lower rates of isolation from both diarrhoeal and healthy stools. No statistically significant difference in the rate of isolation of campylobacter was observed between diarrhoeal and healthy periods in any of the age groups. 


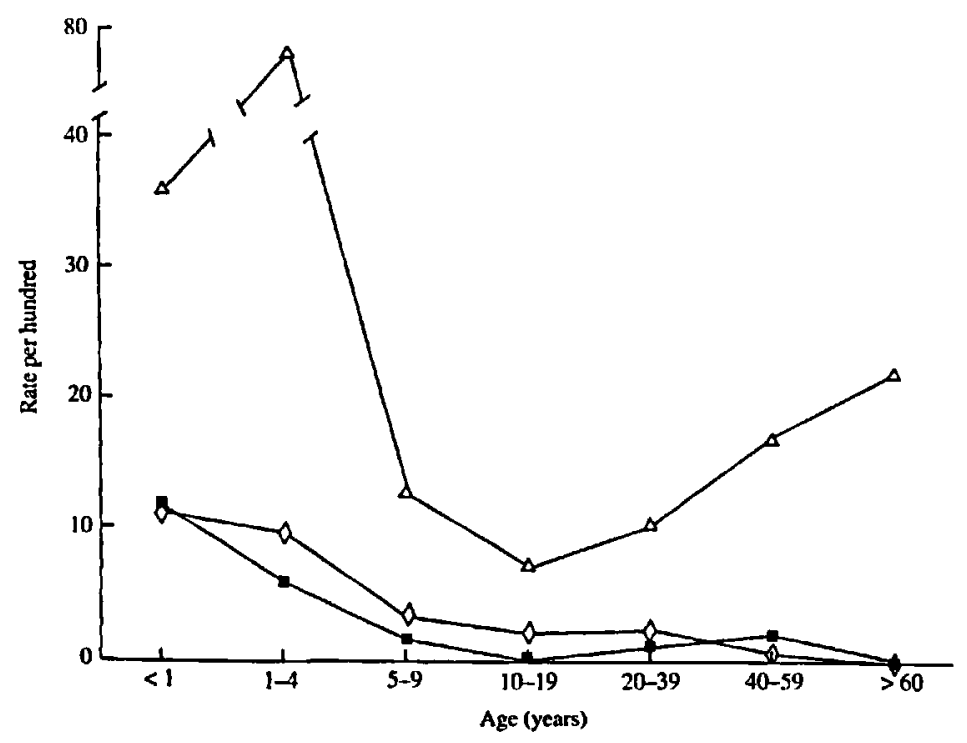

Fig. 1. Age-specific attack rates of all diarrhoeas $(\Delta)$, campylobacter-associated diarrhoea (a) and campylobacter isolation without diarrhoea $(\diamond)$.

Table 1. Clustering of campylobacter infections within study families

\begin{tabular}{|c|c|c|c|}
\hline \multirow[b]{2}{*}{ Study families } & \multicolumn{3}{|c|}{$\begin{array}{l}\text { No. of occasions when campylobacter } \\
\text { isolated in a family }\end{array}$} \\
\hline & $\begin{array}{c}\text { From a single } \\
\text { person }(\%)\end{array}$ & $\begin{array}{l}\text { From more than } \\
\text { one person }(\%)\end{array}$ & $\begin{array}{c}\text { Total } \\
\text { occasions (\%) }\end{array}$ \\
\hline $\begin{array}{l}\text { With campylobacter } \\
\text { diarrhoea }\end{array}$ & $6(75 \cdot 0)$ & $2(25 \cdot 0)$ & 8 \\
\hline $\begin{array}{l}\text { Without campylobacter } \\
\text { diarrhoea }\end{array}$ & $16(72 \cdot 7)$ & $6(27 \cdot 3)$ & 22 \\
\hline Total & $22(73 \cdot 3)$ & $8(20.7)^{*}$ & $30(100.0)$ \\
\hline
\end{tabular}

Table 1 shows clustering of campylobacter infections within the study families in presence and in absence of a campylobacter-associated diarrhoea case in the family. During the period of surveillance, campylobacter was isolated from one or more members of the study families on a total of 30 occasions. On eight such occasions, a campylobacter-associated diarrhoea case was also present in the family. In $22(73 \cdot 3 \%)$ of these 30 occasions, one person in a family was infected and in only eight (26.7\%) was more than one person infected. Presence or absence of a campylobacter-associated diarrhoea case in the family at the time of sampling did not appear to have any effect on this observation. In no instance was there more than one case of campylobacter-associated diarrhoea in a family at any one time. In 8 instances when multiple infections were detected, 18 of 64 persons were positive in 5 families giving an average of a $28 \%$ infection rate amongst the family members.

Isolation of campylobacter from pet animals and recording of human infection 
Table 2. Isolation of campylobacter from domestic animals and the relationship to human campylobacteriosis

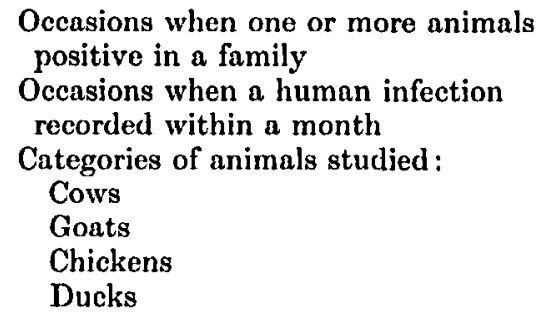

$\begin{array}{cc}\begin{array}{c}\text { No. of occasions } \\ \text { or samples positive/ } \\ \text { total number of }\end{array} & \\ \text { occasions or samples } & \text { Percentage } \\ 26 / 134 & 19 \cdot 4 \\ 2 / 26 & \\ & 7 \cdot 7 \\ 3 / 277 & \\ 4 / 139 & 1 \cdot 1 \\ 45 / 174 & 2 \cdot 9 \\ 1 / 22 & 25 \cdot 9 \\ & 4 \cdot 5\end{array}$

in relation to the presence of infected animal(s) in the study families is summarized in Table 2. Campylobacter was isolated in varying proportions from all categories of domestic animals studied including cows, goats, chickens and ducks. The highest rate of isolation was obtained from chickens (25.9\%). Sampling of animals in these families was undertaken on 134 occasions and one or more was positive in $26(19 \cdot 4 \%)$. However, only on $2(7 \cdot 7 \%)$ of these 26 occasions could a human infection be detected within a period of 30 days after a relevant animal was found to be positive.

Details of the bacterial and parasitic agents isolated from 70 diarrhoeal episodes are presented in Table 3 . The overall isolation rate of any pathogen was $41.5 \%$ and of campylobacters was $11.4 \%$. In $7 \cdot 1 \%$ cases, campylobacter was the sole pathogen isolated. However, in another $4.3 \%$ of the episodes, the organism was isolated in association with enteropathogenic $E$. coli $(2 \cdot 9 \%)$ and Shigella flexneri $(1 \cdot 4 \%)$.

\section{DISCUSSION}

In the developed countries, campylobacters have either been isolated from diarrhoea patients $[2,14]$ or from their contacts exposed to the same suspected vehicle of transmission but rarely from other healthy individuals [7]. Data available from developing countries suggest that the organism has been isolated from both diarrhoeal and healthy children in relatively high proportion $[3,15,16]$. In the present study we observed comparable results in a rural community near Calcutta where campylobacter was isolated with equal frequency in all age groups during diarrhoeal and healthy periods in the same cohort. Bokkenheuser and colleagues [15] observed a significantly higher prevalence of $C$. jejuni in 0-8 months old children with diarrhoea compared to asymptomatic children suggesting an actiological role for this organism in causing diarrhoea in this age

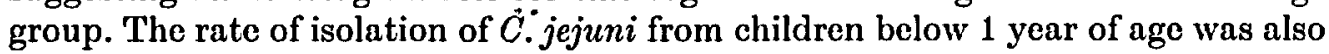
highest in this community although we found no significant difference during diarrhoeal and control periods. Nevertheless, further studies are needed to explain greater susceptibility of infants to infection with campylobacter. In the industrialized countries where studies on campylobacter enteritis are mainly 
Table 3. Profile of bacterial and parasitic agents isolated from 70 diarrhoeal episodes

Agents isolated
Campylobacter jejuni only
C. jejuni+EPEC
C. jejuni+S. flexneri
EPEC only
S. sonnei
S. flexneri
S. boydii
G. lamblia
E. histolytica
E. coli
A. lumbricoides
No isolation

$\begin{array}{ccc}\text { Number } & \text { Percentage } & \begin{array}{c}\text { Cumulative } \\ \text { percentage }\end{array} \\ 5 & 7 \cdot 1 & 7 \cdot 1 \\ 2 & 2 \cdot 9 & 10 \cdot 0 \\ 1 & 1 \cdot 4 & 11 \cdot 4 \\ 4 & 5 \cdot 7 & 17 \cdot 1 \\ 2 & 2 \cdot 9 & 20 \cdot 0 \\ 2 & 2 \cdot 9 & 22 \cdot 9 \\ 2 & 2 \cdot 9 & 25 \cdot 8 \\ 2 & 2 \cdot 9 & 28 \cdot 7 \\ 4 & 5 \cdot 7 & 34 \cdot 4 \\ 1 & 1 \cdot 4 & 35 \cdot 8 \\ 4 & 5 \cdot 7 & 41.5 \\ 41 & 58 \cdot 6 & 100 \cdot 1\end{array}$

based on hospital settings most of the isolates were obtained in the summer months $[1,17]$. However, we isolated campylobacter from one source or another throughout the year, indicating the continuous presence of the organism in the environs of this community.

Campylobacter enteritis is a recognized zoonosis in the developed countries where greater opportunities exist for the organism to be foodborne [18]. However, the organism is killed by heating to $60^{\circ} \mathrm{C}$ for $15 \mathrm{~min}$ [19], and therefore is unlikely to withstand the usual cooking process practised in India. During this study, we failed to record human infection within a month following detection of one or more infected animals in the family. Moreover, not a single co-primary or secondary case of campylobacter enteritis was detected, the infections mostly occurring singly. It appears that neither campylobacter enteritis nor subclinical infection comes in this community either from a common source or from casual contact with an infected or colonized animal. Nevertheless, the organism is present in the domestic animals and there is a high carriage rate in chickens. These are normally free-living birds and are not restricted within the confines of any single family. They deposit fresh droppings everywhere including open corridors where the young children crawl. Further studies are needed to delineate the exact mode of transmission of this organism and the extent of environmental contamination so that suitable intervention measures can be eventually evolved.

As observed in other studies of the developing countries $[3,6,16] 3$ of the 8 episodes recorded during this study had other enteropathogens in addition to campylobacter indicating the high level of environmental contamination in which the children of developing countries reside.

\section{ACKNOWLEDGEMENTS}

The authors are grateful to $\mathrm{Dr}$ M. B. Skirrow for his active involvement and guidance during analysis of the data in meaningful ways. The invaluable technical support of the staff of Epidemiology and Microbiology Divisions of the National Institute of Cholera and Enteric Diseases, Calcutta, are thankfully acknowledged. 


\section{REFERENCES}

1. Butzler JP, Dekeyser P, Detrain MG, Dehaen F. Related vibrio in stools. J Pediatric 1973; 82: 493-5.

2. Skirrow MIB. Campylobacter enteritis: a 'new' disease. Br Med J 1977; 2: 9-11.

3. Blaser MJ, Glass RI, Huq MI, Stoll B, Kibriya GM, Alim A. Isolation of Campylobacler fetus subsp. jejuni from Bangladeshi children. J Clin Microbiol 1980; 12: 744-7.

4. Communicable Disease Surveillance Centre. Campylobacter infections, 1977-80. Br Med J $1981 ; 282: 1484$.

5. Mosenthal AC, Mones RL, Bokkenheuser VD. Campylobacter fetus jejuni enteritis in New York City. NY J Med 1981; 81: 321-3.

6. Nair GB, Bhattacharya SK, Pal SC. Isolation and characterization of Campylobacter jejuni from acute diarrhoeal cases in Calcutta. Trans $R$ Soc Trop Med Hyg 1983; 77: 474-6.

7. Symonds J. Campylobacter enteritis in the community. Br Med J 1983; 286: 243-4.

8. Blaser MI, Cravens J, Powers BW, Wang WL. Campylobacter enteritis associated with eanine infection. Lancet 1978; ii: 979-82.

9. Blaser MJ, Checko P, Bopp C, Bruce A, Hughes JM. Campylobacter enteritis associated with foodborne transmission. Am J Epidemiol 1982; 116: 886-94.

10. Skirrow MIB, Benjamin J. '1001' Campylobacters: cultural characteristics of intestinal campylobacters from man and animals. J Hyg 1980; 85: 427-42.

11. Farmer III JJ, Hickman-Brenner FW, Kelly MT. Vibrio In: Lennette EH, ed. Manual of clinical microbiology; 4th ed. American Society for Microbiology, Washington DC, USA, 1085 : 282-301.

12. Kelly MT, Brenner DJ, Farmer III JJ. Enterobacteriaceae In: Lennette EH, ed. Manual of clinical microbiology, 4th ed. American Society for Microbiology, Washington DC, USA, 1985: 263-77.

13. Ritchie LS. An ether sedimentation technique for routine stool examinations. Bull U.S. Army Medical Department 1984; 8: 326.

14. Svedhem A, Kaijser B. Campylobacter fetus subspecies jejuni: a common cause of diarrhoea in Sweden. $J$ Infec Dis $1980 ; 142: 353-0$.

15. Bokkenheuser VD, Richardson NJ, Bryner JH, et al. Detection of enteric campylobacteriosis in children. J Clin Microbiol 1979; 9: 227.

16. Rajan DP, Mathan VI. Prevalence of Campylobacter fetus jejuni in healthy populations in southern India. J Clin Microbiol 1982; 15 : 749-51.

17. Blaser MIJ, Berkowitz ID, LaForce FM, Cravens J, Reller LB, Wang WL. Campylobacter enteritis: clinical and epidemiologic features. Ann Int Med 1979; 91 : 179-85.

18. Simmons NA, Gibbs FJ. Campylobacter subsp. in ovenready poultry. J Infec 1979; 1: $159-62$.

19. Svedhem A., Kaijser B, Sjorgren E. The occurrence of Campylobacter jejuni in fresh food and survival under different conditions. J Hyg 1981; 87 : 421-5. 